\title{
Percutaneous device closure of atrial septal defect in HIV-positive patient: a challenge for interventionist
}

\author{
Natraj Setty H.S., M.C. Yeriswamy, VeereshPatil, Jayashree Kharge, T.R. Raghu, P.C. Raghavendra, \\ Rahul Patil, B.K. Geetha, C.N. Manjunath
}

Sri Jayadeva Institute of Cardiovascular Sciences and Research, Bangalore, Karnataka, India

\begin{abstract}
Atrial septal defect (ASD) is one of the most common congenital heart defects. Intracardiac repair via midline sternotomy or right thoracotomy and cardiopulmonary bypass have been considered the standard treatment for the closure of atrial septal defects, but transcatheter closure with Amplatzer septal occluder has recently become an alternative option. Transcatheter device closure of secundum ASD is a more than a decade old technology. This has become an alternative to surgical therapy, and has been regarded as generally safe and effective device closure. Device embolization is a potential complication of every attempted ASD closure, and the causative factors include undersized device, floppy rim, and operator-related technical issues, such as malposition during a "push-pull" maneuver. In this paper, we report a 32-year-old HIV positive female patient who presented with gradual onsite of dyspnea, NYHA class II, and successfully underwent a device closure of large atrial septal defect.
\end{abstract}

HIV AIDS Rev 2020; 19, 4: 289-291 DOI: https://doi.org/10.5114/hivar.2020.101755

Key words: atrial septal defect, HIV, congenital heart defects, echocardiography.

\section{Case description}

A 32-year-old female patient presented with dyspnea on exertion (NYHA class II) and fatigue for one year. An examination revealed the presence of wide fixed splitting. A routine investigation was normal, and VDRL (Venereal Diseases Research Laboratory) and connective tissue profiles were also normal. The patient was a known human immunodeficiency virus (HIV)-positive case on antiretroviral therapy. Her CD4 count was 690 , and chest X-ray showed cardiomegaly. An 2D echocardiography apical four-chamber view indicated dilated right atrium (RA) and right ventricle (RV) ostium secundum atrial septal defect (ASD) measuring $3 \mathrm{~cm}$. Transesophageal echocardiography demonstrated RA and RV di- lated normal pulmonary venous drainage ostium secundum ASD measuring $3 \mathrm{~cm}$, atrioventricular rim measuring $1.5 \mathrm{~cm}$, atrial rim measuring $1.5 \mathrm{~cm}$, interior vena cava rim measuring $1.6 \mathrm{~cm}$, and superior vena cava rim measuring $1.3 \mathrm{~cm}$ (mean pulmonary artery pressure-20mm (PAP)). Successful large atrial septal defect device closure was done using a $32 \mathrm{~mm}$ Lifetech ASD device occluder. The patient improved symptomatically and is on regular follow-up for six months.

\section{Discussion}

An atrial septal defect is a common congenital heart disease, and nearly $8 \%$ to $10 \%$ of all congenital heart diseases and $30 \%$ to $40 \%$ of adults with congenital heart diseases

Article history:

Received: 11.02.2020

Received in revised form: 18.02.2020

Accepted: 17.05.2020

Available online: 30.11 .2020
International Journal of HIV-Related Problems HIV \& AIDS Re vi e w 

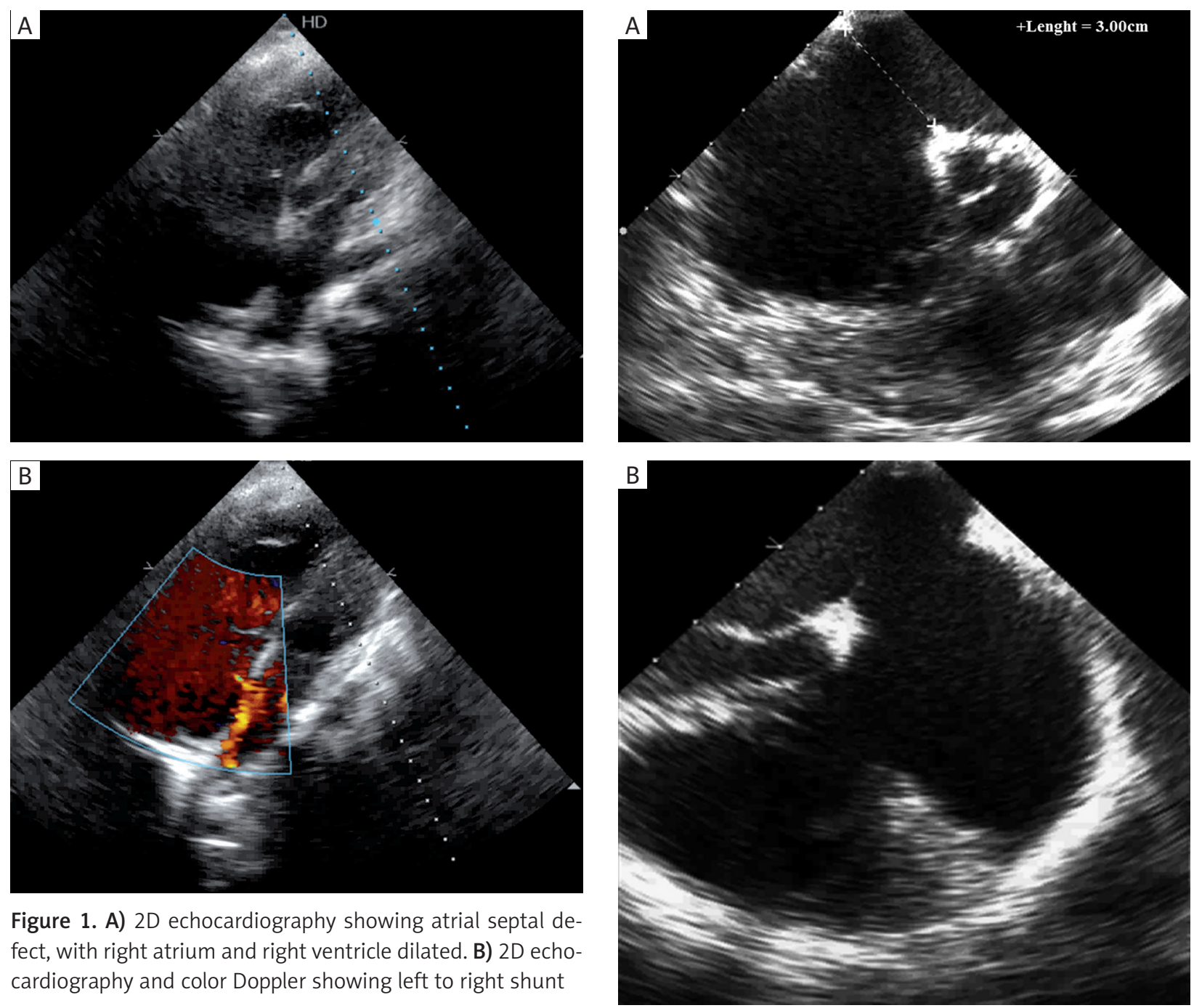

Figure 1. A) 2D echocardiography showing atrial septal defect, with right atrium and right ventricle dilated. B) 2D echocardiography and color Doppler showing left to right shunt

(CHDs) are diagnosed with atrial septal defect [1]. Percutaneous device closure and minimally invasive transthoracic device closure have improved markedly, and have achieved satisfactory outcomes in some patients with atrial septal defect, which gradually become another standard treatment for ostium secundum atrial septal defect [2]. ASD, although recognized as a relatively benign form of cardiac defect, if left untreated, can eventually contribute to significant morbidity and mortality [3]. Unrepaired ASD can lead to right ventricular volume overload, which results in right heart failure, elevated pulmonary vascular resistance, systemic embolism, and atrial arrhythmias [4]. Transcatheter device closure of secundum ASD is a maturing technology. This therapy has become a well-accepted alternative to surgical treatment, and has been regarded as generally safe and effective [5]. Echocardiographic evaluation can confirm the diagnosis. Moreover, echocardiography is not only important for the diagnosis and determining suitability for device closure. It is the primary modality, on which the interventionist relies during a closure procedure, and the determination can be made whether a particular ASD is suitable for transcatheter closure [6]. Even though some reports have mentioned

Figure 2. A) Transesophageal echocardiography (TEE) showing right atrium and right ventricle dilated, atrial septal defect measuring $3 \mathrm{~cm}$; B) TEE showing large atrial septal defect

the increased incidence of congenital heart diseases in congenitally-infected children with HIV, most of the large series across the world have not shown any increased incidence of congenital heart disease in those children [7]. Cardiac disease associated with HIV include congestive heart failure, dilated cardiomyopathy, pericardial effusion with or without tamponade, arrhythmias, marantic, and infective endocarditis [8]. The introduction of highly active antiretroviral therapy (HAART) regimens can alter the cardiovascular manifestations of HIV. HAART has significantly modified the course of HIV disease, extended patients' survival, and improved quality of life of HIV-infected patients [9].

\section{Conclusions}

Percutaneous transcatheter device closure is one of the most common procedures performed in atrial septal defect. The morbidity and mortality rates of patients can significantly 


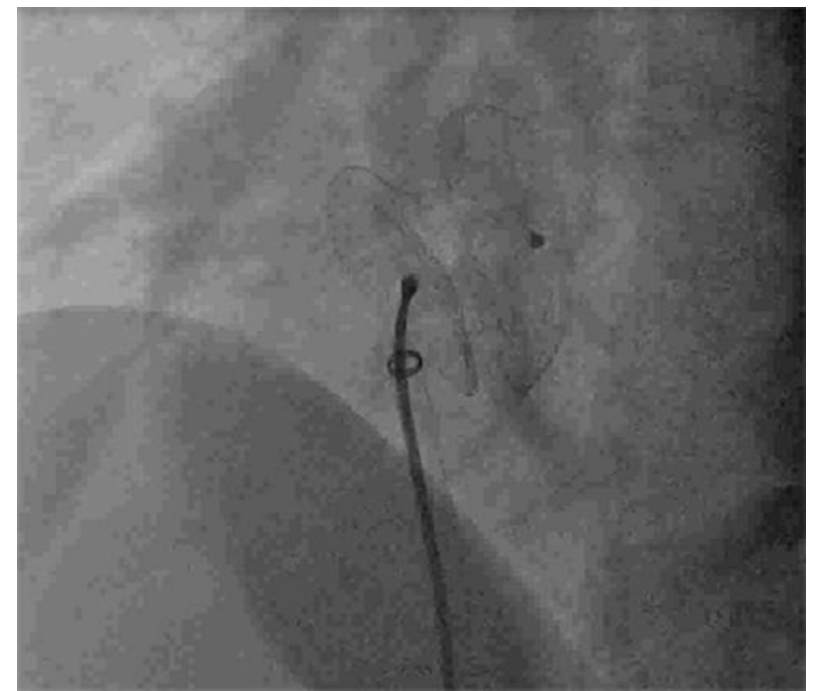

Figure 3. Angiographic demonstration of ASD Device closure

decrease, if timely intervened. The role of infection and inflammation in non-HIV-related cardiovascular disease is starting to be recognized, and HIV-related heart disease may provide the basis for rational therapeutic strategies and improved care. Clinicians should be aware of the various cardiovascular complications of HIV infection, especially associated coronary artery disease and congenital heart defects. They should aggressively treat all risk factors occurring in their HIV-infected patients.

\section{Conflict of interest}

The authors declare no conflict of interest with respect to the research, authorship, and/or publication of this article.

\section{References}

1. Chu MW, Losenno KL, Fox SA, et al. Clinical outcomes of minimally invasive endoscopic and conventional sternotomy approaches for atrial septal defect repair. Can J Surg 2014; 57: E75-81.

2. Petit CJ, Justino H, Pignatelli RH, et al. Percutaneous atrial septal defect closure in infants and toddlers: predictors of success. Pediatr Cardiol 2013; 34: 220-225.

3. Campbell M. Natural history of atrial septal defect. Br Heart J 1970; 32: 820-826.

4. Craig RJ, Selzer A. Natural history and prognosis of atrial septal defect. Circulation 1968; 37: 805-815.

5. Moore J, Hegde S, El-Said H, et al. Transcatheter device closure of atrial septal defects: a safety review. JACC Cardiovasc Interv 2013; 6: 433-442.

6. Podnar T, Martanovic P, Gavora P, et al. Morphological variations of secundum-type atrial septal defects: feasibility for percutaneous closure using Amplatzer septal occluders. Catheter Cardiovasc Interv 2001; 53: 386-391.

7. Lai WW, Lipshultz SE, Easley KA, et al. Prevalence of congenital cardiovascular malformations in children of human immunodeficiency virus-infected women: the prospective P2C2 HIV multicenter study. P2C2 HIV Study Group, National Heart, Lung, and Blood Institute, Bethesda, Maryland. J Am Coll Cardiol 1998; 32: 1749-1755.
8. Diógenes MSB, Succi R, Machado DM, et al. Cardiac longitudinal study of children perinatally exposed to human immunodeficiency type 1. Arq Bras Cardiol 2005; 85: 233-240.

9. Barbaro G, Fisher SD, Lipshultz SE. Pathogenesis of HIV-associated cardiovascular complications. Lancet Infect Dis 2001; 1: 115-124. 